\title{
Stress distribution ahead of mechanized longwall top coal caving face with great cutting height
}

\author{
Tung Manh Bui ${ }^{1,}{ }^{*}$, Hung Phi Nguyen ${ }^{1}$, Tuan Van Nguyen ${ }^{2}$ \\ ${ }^{1}$ Hanoi University of Mining and Geology, Hanoi, Vietnam \\ 2 Vietnam National Coal - Mineral Industries Holding Corporation Limited, Hanoi, Vietnam
}

\begin{abstract}
ARTICLE INFO
ABSTRACT

Article history:

Received $18^{\text {th }}$ Feb. 2021

Revised 09th May 2021

Accepted $15^{\text {th June }} 2021$

Keywords:

Cutting height,

Longwall top coal caving,

Recovery efficiency,

Top coal,

Front abutment stress.

Longwall Top Coal Caving (LTCC) technology with great cutting height is a new development trend in mining thick coal seam. The cutting height of LTCC face typically ranges from $2.8 \mathrm{~m}$ to $3.2 \mathrm{~m}$ in many coal mining countries, but it recently reaches up to $4.2 \mathrm{~m}$ in many coal mines in China. Because the cutting height increases, the caving height accordingly decreases that changes the stress distribution around coal face and law of roof rock caving. Based on the geological condition of Longwall 4108 at Ping Shou coal mine, ShanXi province, China, this paper presents a modelling of LTCC mining process with a cutting height of $4.2 \mathrm{~m}$ by using the numerical program FLAC3D. From the modelling, the paper presents an analysis of stress distribution ahead of LTCC face with great cutting height. The results show that as the coal face advances, the stress magnitude ahead of coal face increases. The peak front abutment stress moves further away from coal face. The stress concentration ratio increases, and stress concentration zone expands correspondingly. These changes of stress facilitate the failure of top coal, increasing the efficiency of top coal recovery and improving longwall face stability.
\end{abstract}

Copyright (C 2021 Ha noi University of Mining and Geology. All rights reserved.

${ }^{*}$ Corresponding author

E - mail: buimanhtung@humg.edu.vn

DOI:10.46326/JMES.2021.62(5a).02 


\title{
Tạp chí Khoa học Kỹ thuật Mỏ - Địa chất
}

Trang điện tử: http://tapchi.humg.edu.vn

\section{Nghiên cứu quy luật phân bố ứng suất trước gương lò chợ cơ giới hóa hạ trần than nóc với chiều cao khấu lớn}

\author{
Bùi Mạnh Tùng 1, ${ }^{*}$, Nguyễn Phi Hùng ${ }^{1}$, Nguyễn Văn Tuân ${ }^{2}$ \\ 1 Trường Đại học Mỏ - Địa chất, Hà Nội, Việt Nam \\ 2 Tập đoàn Công nghiệp Than - Khoáng sản Việt Nam, Hà Nội, Việt Nam
}

\begin{abstract}
THÔNG TIN BÀI BÁO
TÓM TẮT

\section{Quá trình:}

Nhận bài 18/02/2021

Sưa xong 09/5/2021

Chấp nhận đăng 15/6/2021

\section{Tù̀ khóa:}

Chiều cao khấu,

Công nghệ hạ trần,

Hiệu quả thu hồi,

Than nóc,

Ứng suất phía trước.

Khai thác với chiều cao khấu lớn cho vỉa dày là xu hướng phát triển trong công nghê ha trần than vách. Đa số chiều cao lớp khấu của lò chơ cơ giới hóa hạ trần ở các nước khai thác than trên thế giới dao động từ 2,8 $\mathrm{m}$ đến 3,2 m, nhưng hiện nay ở Trung Quốc đã xuất hiện nhiều lò chợ có chiều cao lớp khấu đạt đến 4,2 m. Khi chiều cao lớp khấu tăng lên, chiều dày lớp than hạ trần giảm xuống, tù đó thay đổi trạng thái phân bố ưng suất xung quanh lò chợ cũng nhu thay đổi quy luật sập đổ của đá vách. Bài báo dựa trên điều kiên đia chất lò chợ 4108 mỏ Ping Shou, ShanXi (Trung Quốc), sử dụng mô hình số hóa FLAC3D, mô phỏng quá trình khai thác lò chợ khi chiều cao lớp khấu là 4,2 m, sau đó tiên hành phân tích quy luật phân bố trang thái ứng suất phía trước gương lò chơ khi chiều cao lớp khấu lớn. Kết quả nghiên cứu cho thấy, giá trị ứng suất phía trước gương lò chợ tùy theo tốc độ tiến gương tăng lên mà cũng tăng lên; vị trí úng suất lớn nhất phía gương dịch chuyển ra xa so với gương than; hệ số ứng suất tập trung theo tốc độ tiến gương cũng tăng lên, vùng ảnh hưởng của ưng suất lớn nhất phía trước gương phát triển rộng hơn, điều đó thuận lợi cho quá trình phá hủy than nóc, tăng hiệu quả thu hồi than nóc cũng như nâng cao độ ổn định của gương lò chớ.
\end{abstract}

C2021 Trường Đại học Mỏ - Địa chất. Tất cả các quyền được bảo đảm.

\section{Mở đầu}

Công nghệ cơ giới hóa hạ trần than nóc là một trong những công nghệ được áp dụng chủ yếu để khai thác than vỉa dày ở các nước tiên tiến trên thế giới. Thực tiễn cho thấy, áp dụng công nghệ này đã

\footnotetext{
*Tác giả liên hệ

E - mail: buimanhtung@humg.edu.vn DOI:10.46326/JMES.2021.62(5a).02
}

nâng cao được sản lượng và năng suất của lò chợ. Tuy nhiên, nhược điểm của công nghệ này là tổn thất than trong quá trình hạ trần than nóc vẫn còn rất lớn (Bùi Mạnh Tùng và nnk., 2016; Tien Dung Le và Xuan Nam Bui, 2019). Nhất là trong một số trường hợp như: khai thác vỉa dày đến rất dày, vỉa có độ kiên cố từ trung bình trở lên thì cơ chế phá hủy, sập đổ và tỷ lệ thu hồi than nóc sẽ bị ảnh hưởng rất lớn. Một trong các giải pháp nhằm nâng cao khả năng phá hủy, sập đổ và hiệu quả thu hồi của khối than nóc là nâng cao chiều cao khấu của 
máy khấu hay còn gọi là chiều cao khấu gương. Thông thường, máy khấu ở lò chợ cơ giới hóa hạ trần than nóc của Trung Quốc có chiều cao khấu từ 2,8 $\div 3,2 \mathrm{~m}$, nhưng hiện nay cũng đã có rất nhiều lò chợ hạ trần than nóc có chiều cao khấu là $4,2 \mathrm{~m}$ như Xinglong Zhuang, TaShan, Da Tong, Ping Shou (Gong Peilin, 2008). Thực tiễn cho thấy, khi chiều cao khấu gương lớn thì tỷ lệ thu hồi chung của lò chợ tăng lên, vì tỷ lệ thu hồi của phần than khấu máy thường đạt đến 98\% (He Fulin và nnk., 2011; Gong và nnk., 2001). Tuy nhiên, tỷ lệ thu hồi phần than lớp vách phụ thuộc vào nhiều yếu tố, trong đó có sự ảnh hưởng của áp lực xung quanh lò chợ. Do đó, cần thiết phải có những nghiên cứu tỉ mỉ về sự phân bố ứng suất xung quanh lò chợ. Trong bài báo này, tác giả sử dụng phần mềm FLAC3D để mô phỏng quá trình khai thác lò chợ cơ giới hóa hạ trần than nóc 4108 mỏ Ping Shou, Shanxi (Trung Quốc), từ đó phân tích trạng thái phân bố ứng suất và dịch động của than và đá phía trước gương lò chợ.

\section{2. Đặc điểm điều kiện địa chất - kỹ thuật lò chợ}

Lò chợ 4108 thuộc vỉa 4, có chiều dài theo đường phương là $2.690 \mathrm{~m}$, chiều dài lò chợ $300 \mathrm{~m}$, diện tích khu vực khai thác là $80.700 \mathrm{~m} 2$, chiều dày vỉa $6,9 \mathrm{~m}$, chiều cao khấu là $3,5 \mathrm{~m}$, chiều cao lớp hạ trần 3,4 m, tỷ lệ khấu - hạ trần 1:0,97, bước tiến gương là $0,8 \mathrm{~m}$. Chiều dày vách trực tiếp từ $5,51 \div 50,33 \mathrm{~m}$, trung bình $11,88 \mathrm{~m}$, mức độ nứt nẻ phát triển tương đối mạnh, thành phần chủ yếu là đá thạch anh. Đá trụ trực tiếp dày $0,5 \div 4,84 \mathrm{~m}$, trung bình $2,88 \mathrm{~m}$. Đá trụ cơ bản là đá cát kết, bột kết và thạch anh, chiều dày $0,74 \div 9,8 \mathrm{~m}$, đá thuộc

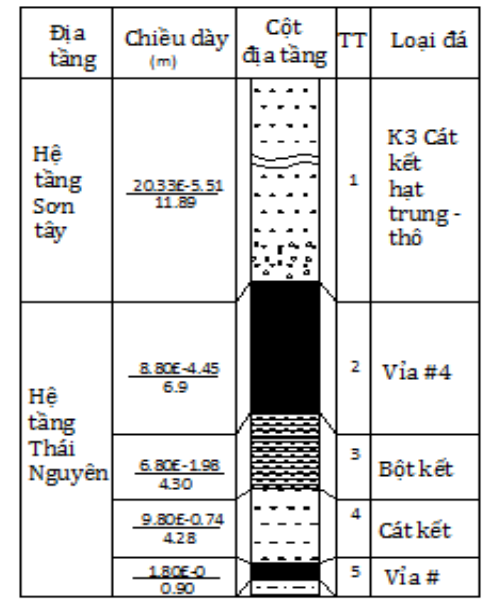

Hình 1. Địa tầng khu vực khai thác. loại kiên cố trung bình. Theo tài liệu báo cáo thăm dò địa chất tại mỏ Ping Shuo, địa tầng và sơ đồ chuẩn bị khu vực khai thác được thể hiện trên các Hình 1 và 2 .

\section{Nghiên cứu quy luật phân bố ứng suất xung quanh lò chợ cơ giói hóa hạ trần than nóc khi chiều cao khấu gương lớn}

\subsection{Xây dụng mô hình}

Căn cứ vào điều kiện địa chất lò chợ 4108 mỏ Ping Shou, sử dụng phương pháp nghiên cứu mô hình mô phỏng số hóa bằng phần mềm FLAC3D, tiến hành phân tích ảnh hưởng khi chiều cao khấu gương lớn đến khả năng phá hủy, sập đổ của than và đá vách trong lò chợ cũng như sự phân bố ứng suất xung quanh lò chợ. Chiều dày của vỉa than và các lớp đá xung quanh mô hình mô phỏng được lấy theo số liệu thực tế của mỏ. Do góc dốc vỉa rất nhỏ và được coi như vỉa nằm ngang, do vậy thiết kế mô hình không xem xét đến yếu tố góc dốc vỉa. Ranh giới 4 mặt xung quanh và mặt đáy áp dụng điều kiện biên dịch vị, tức là dịch vị theo hướng pháp tuyến bằng 0 . Mặt phía trên áp dụng điều kiện biên ứng suất. Kích thước mô hình là $250 \mathrm{~m} \mathrm{x}$ 270 m x 97 m (dài x rộng x cao), tải trọng của các lớp đất đá phía trên được bù bằng tải trọng tương đương và được xác định theo công thức (1):

$$
\sigma=\sum H \rho g
$$

Trong đó: $H$ - chiều dày của các lớp đất đá phía trên, $\mathrm{m} ; \rho$ - gia tốc trọng trường, lấy $\rho=$ $9,81 \mathrm{~m} / \mathrm{s}^{2}$.

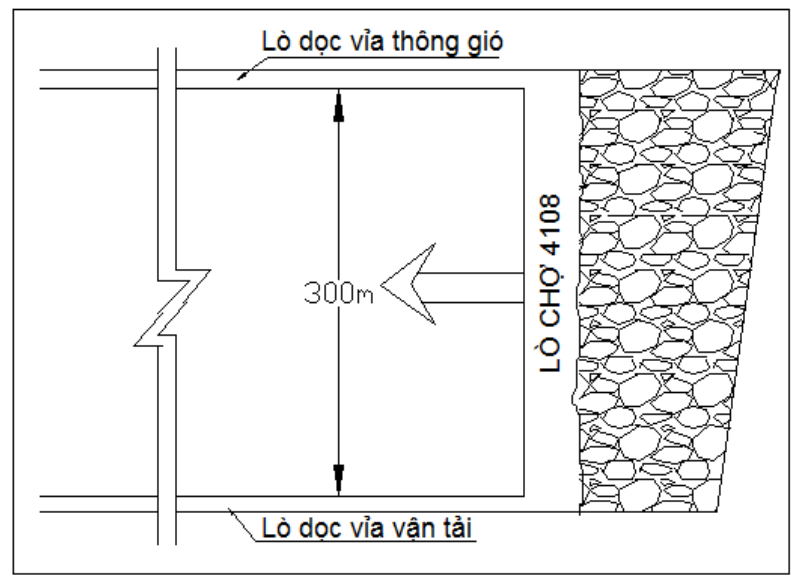

Hình 2. Sơ đồ chuẩn bị lò chợ 4108. 
Tham số cơ lý của đá được xác định theo giá trị trung bình phân loại đất đá của mỏ.

Phương án mô phỏng chiều cao khấu của lò chợ là 3,5 m, chiều cao hạ trần là 3,5 m, chiều dài khai thác theo đường phương là $200 \mathrm{~m}$. Tính chất cơ lý của than và đá xung quanh được thể hiện ở Bảng 1, mô hình ban đầu được thể hiện ở Hình 3.

Bảng 1. Tham số của đất đá trong mô hình.

\begin{tabular}{|l|c|c|c|c|c|c|}
\hline \multicolumn{1}{|c|}{ Tên lớp } & $\begin{array}{c}\text { Mật độ } \\
\mathrm{d} / \mathrm{Nm}^{3}\end{array}$ & $\begin{array}{c}\text { Mô đun kháng cắt } \\
\text { K/GPa }\end{array}$ & $\begin{array}{c}\text { Tronng lượng } \\
\text { thế tích G/GPa }\end{array}$ & $\begin{array}{c}\text { Lực dính kết } \\
\mathrm{C} / \mathrm{MPa}\end{array}$ & $\begin{array}{c}\text { Góc nội } \\
\text { ma sát f/0 }\end{array}$ & $\begin{array}{c}\text { Cuờng độ kháng } \\
\text { kéo t/MPa }\end{array}$ \\
\hline Vách cơ bản & 2500 & 32,49 & 9,67 & 6,37 & 28 & 1,31 \\
\hline Vách trực tiếp & 2500 & 25,5 & 10 & 6,12 & 38 & 1,3 \\
\hline Vỉa than & 1400 & 6,27 & 1,2 & 1 & 33 & 0,3 \\
\hline Trụ trực tiếp & 67,87 & 23,6 & 3 & 15 & 23 & 1,93 \\
\hline Trụ cơ bản & 93,85 & 34,65 & 2,72 & 15,91 & 29 & 2,05 \\
\hline
\end{tabular}

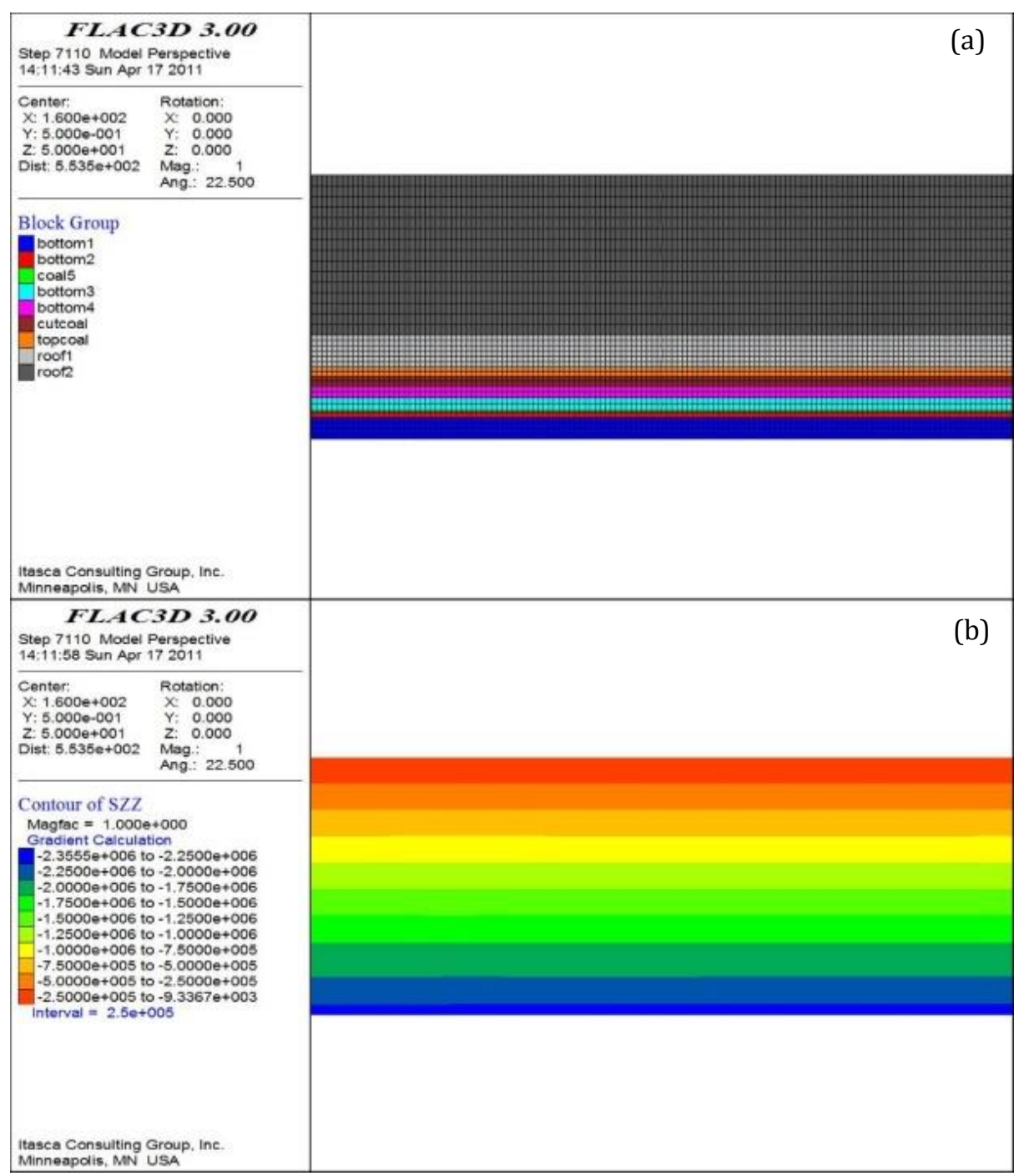

Hình 3. Mô hình mô phỏng quá trình khai thác lò chọ.

(a) Xây dựng mô hình; (b) Ứng suất ban đầu. 


\subsection{Phân tích úng suất xung quanh lò chọ’}

Trên mô hình mô phỏng quá trình tiến gương lò chợ, mỗi lần tiến gương là $20 \mathrm{~m}$, số lần tiến gương được thực hiện là 10 lần, tổng chiều dài tiến gương lò chợ là $200 \mathrm{~m}$. Ứng suất phía trước gương lò chợ theo các bước tiến gương được thể hiện tại Hình 4. Điều này cho thấy, theo mức độ dịch chuyển của gương lò chợ, giá trị ứng suất tập trung phía trước gương lò chợ cũng tăng lên, khi chiều dài tiến gương là $20 \mathrm{~m}$ thì giá trị ứng suất lớn nhất là $2,27 \mathrm{MPa}$, khi chiều dài tiến gương đạt $200 \mathrm{~m}$ thì giá trị ứng suất lớn nhất phía trước gương lò chợ là 5,35 MPa tăng 2,35 lần. Từ vị trí bắt đầu khai thác cho đến $140 \mathrm{~m}$ thì vị trí ứng suất lớn nhất phía trước gương lò chợ tăng từ $2 \div 4 \mathrm{~m}$, khi chiều dài tiến gương lò chợ bắt đầu từ $140 \mathrm{~m}$ trở lên thì vị trí ứng suất lớn nhất trước gương lò chợ dần ổn định với khoảng cách so với gương than là $6 \mathrm{~m}$. Giá trị và vị trí ứng suất phía trước gương lò chợ thể hiện tại Bảng 2 và các Hình 5 và 6 .

Vùng dịch động của đá vách trước gương lò chợ tùy theo tốc độ tiến gương tăng lên mà cũng tăng lên. Khi lò chợ ở bước khấu thứ nhất, vùng dịch động của đá vách trước gương lò chợ là $8 \mathrm{~m}$ sau đó tăng dần lên và khi vị trí gương lò chợ 140 $m$ thì vùng dịch động của đá vách phía trước đạt giá trị lớn nhất là $30 \mathrm{~m}$, sau đó giảm dần và ổn định ở khoảng cách $22 \mathrm{~m}$. Hệ số ứng suất tập trung cũng tương ứng tăng lên.

Như vậy có thể thấy, khi chiều cao lớp khấu lớn, giá trị ứng suất phía trước gương, vị trí ứng suất lớn nhất phía gương dịch chuyển ra xa so với gương than, hệ số ứng suất tập trung cũng theo tốc độ tiến gương mà cũng tăng lên, vùng ảnh hưởng của ứng suất lớn nhất phía trước gương phát triển rộng hơn, điều đó thuận lợi cho quá trình phá hủy than nóc, tăng hiệu quả thu hồi than nóc cũng như nâng cao độ ổn định của gương lò chợ.

\section{Kết luận}

Bài báo sử dụng mô hình số hóa tiến hành mô phỏng quá trình khai thác lò chợ với chiều cao lớp khấu là $4,2 \mathrm{~m}$. Căn cứ vào kết quả mô hình cho thấy, giá trị ứng suất phía trước gương lò chợ tùy theo tốc độ tiến gương tăng mà cũng tăng lên, vị trí ứng suất lớn nhất phía gương dịch chuyển dần xa so với gương than, giá trị lớn nhất đạt $5,53 \mathrm{MPa}$, trung bình 3,3 Mpa.

Hệ số ứng suất tập trung cũng theo tốc độ tiến gương mà cũng tăng lên, hệ số ứng suất tập trung tăng từ 1,01 đến 2,46 trung bình đạt 1.47 . Vùng ảnh hưởng của ứng suất lớn nhất phía trước gương mở rộng hơn, tại vị trí tiến gương $140 \mathrm{~m}$ đạt $30 \mathrm{~m}$. Do vậy, tăng chiều cao khấu có thể tạo điều kiện thuận lợi cho quá trình phá hủy của khối than nóc, từ đó nâng cao được hiệu qua thu hồi trong khai thác lò chợ.

\section{Lò̀i cảm ơn}

Xin được chân thành cảm ơn sự giúp đỡ của Trung tâm Khoa học - Kỹ thuật Mỏ, Trường Đại học Mỏ và Công nghệ Trung Quốc đã cung cấp các tài liệu địa chất và phần mềm ứng dụng để hoàn thành nội dung bài báo này.

\section{Đóng góp của các tác giả}

Bùi Mạnh Tùng - hình thành ý tưởng, cấu trúc bài báo, thu thập số liệu; Nguyễn Phi Hùng, Nguyễn Văn Tuân - mô phỏng phần mềm và hoàn thiện bản thảo bài báo.

Bảng 2. Bảng giá trị và vị trí ứng suất phía trước gương lò chợ.

\begin{tabular}{|l|c|c|c|c|c|c|c|c|c|c|}
\hline \multicolumn{1}{|c|}{$\begin{array}{c}\text { Khoảng cách tiến gương } \\
\text { lò chợ (m) }\end{array}$} & 20 & 40 & 60 & 80 & 100 & 120 & 140 & 160 & 180 & 200 \\
\hline Giá trị ứng suất lớn nhất (MPa) & 2,27 & 2,52 & 2,81 & 3,08 & 3,28 & 3,33 & 3,26 & 3,41 & 3,5 & 5,53 \\
\hline Vị trí ứng suất lớn nhất (m) & 2 & 2 & 2 & 4 & 4 & 4 & 6 & 6 & 6 & 6 \\
\hline Phạm vi ảnh hưởng (m) & 8 & 14 & 12 & 18 & 26 & 28 & 30 & 22 & 22 & 22 \\
\hline Hệ số tập trung ứng suất & 1,01 & 1,12 & 1,25 & 1,37 & 1,46 & 1,48 & 1,45 & 1,52 & 1,56 & 2,46 \\
\hline
\end{tabular}




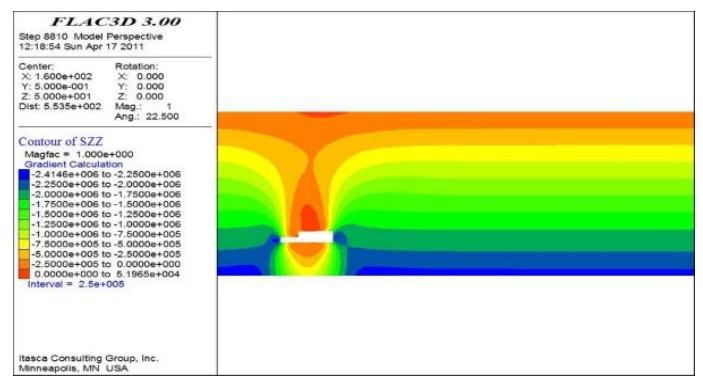

(a) Lò chọ tiến gương $20 \mathrm{~m}$.

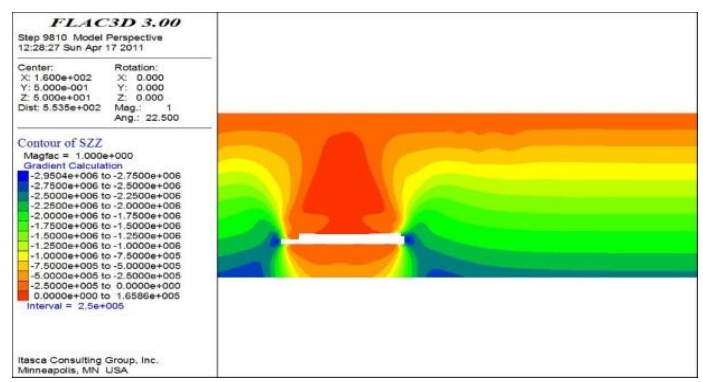

(c) Lò chợ tiến gương $60 \mathrm{~m}$.

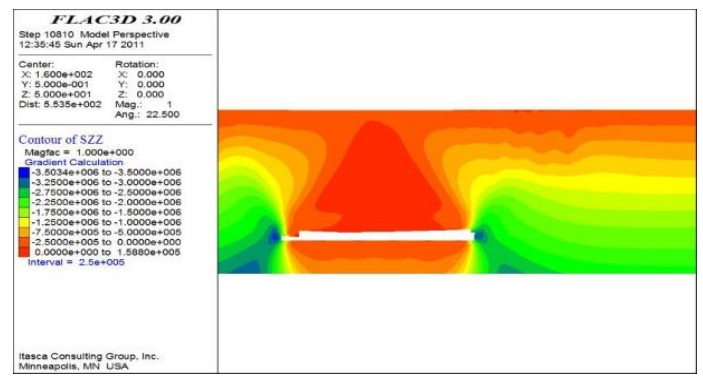

(e) Lò chọ tiến gương $100 \mathrm{~m}$.

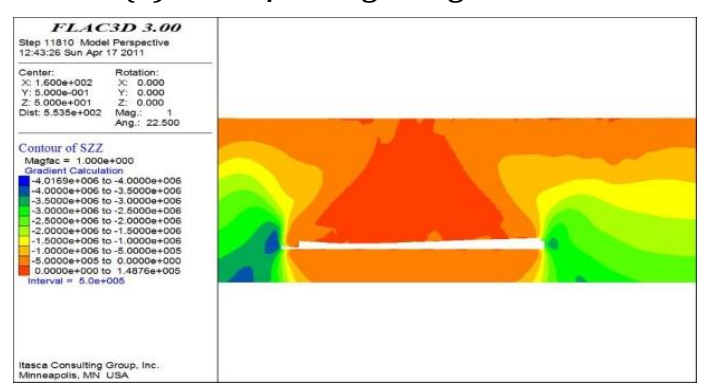

(g) Lò chợ tiến gương 140m.

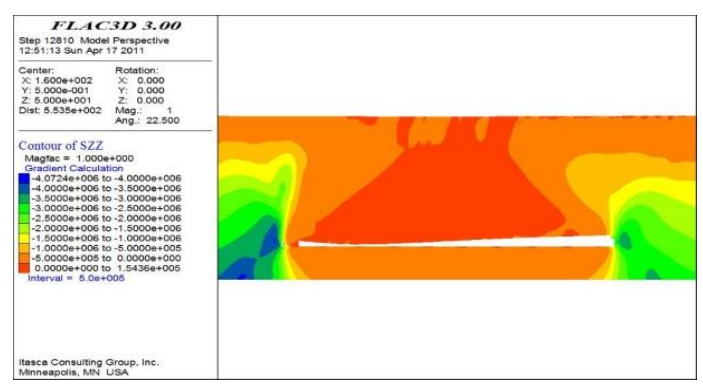

(i) Lò chợ tiến gương $180 \mathrm{~m}$.

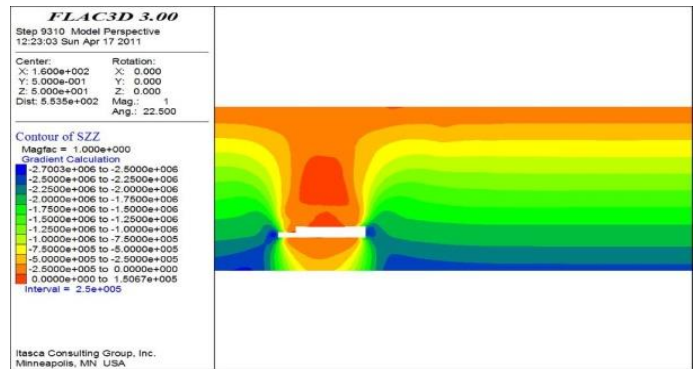

(b) Lò chợ tiến gương $40 \mathrm{~m}$.

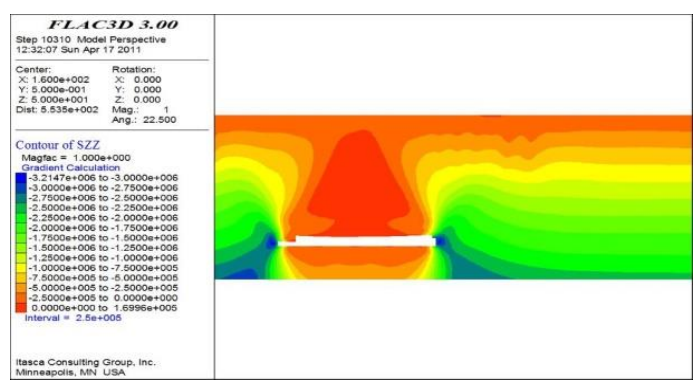

(d) Lò chợ tiến gương $80 \mathrm{~m}$.

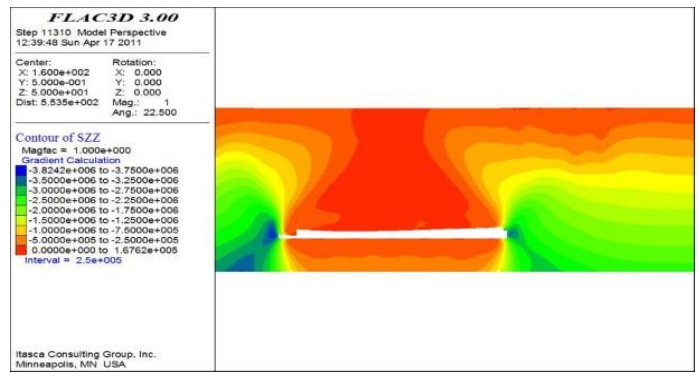

(f) Lò chợ tiến gương $120 \mathrm{~m}$.

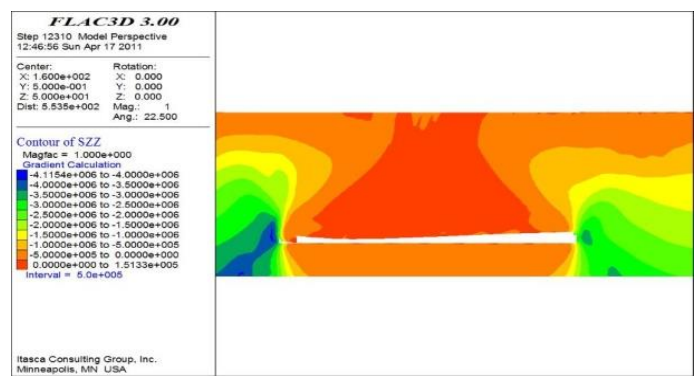

(h) Lò chợ tiến gương $160 \mathrm{~m}$.

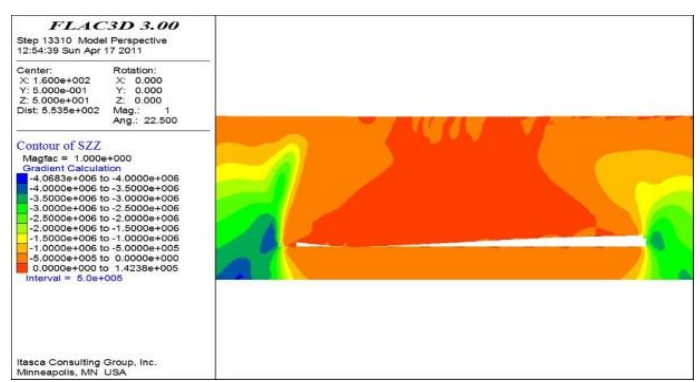

(k) Lò chợ tiến gương $200 \mathrm{~m}$.

Hình 4. Phân bố úng suất phía trước gương lò chợ khi chiều dài thay đổi. 


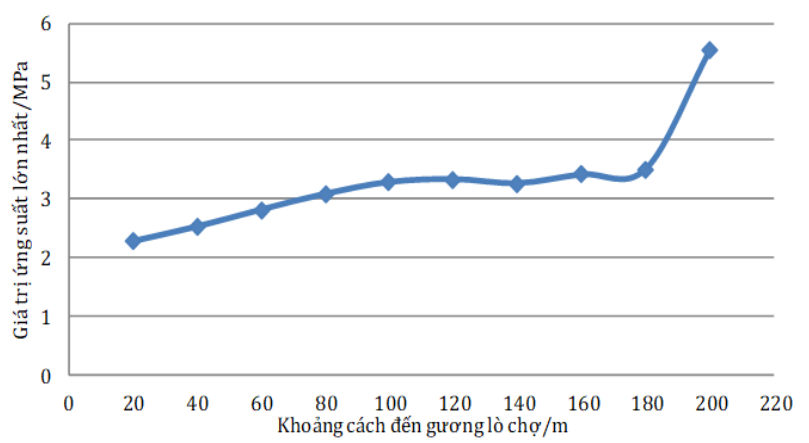

Hình 5. Sự phân bố ứng suất lớn nhất phía trước gương lò chọ.

\section{Tài liệu tham khảo}

Bùi Mạnh Tùng, Nguyễn Phi Hùng, Nguyễn Văn Thịnh, (2016). Nghiên cứu hoàn thiện các thông số công nghệ nhằm nâng cao hiệu quả khai thác than lò chợ dài hạ trần cơ giới hóa vỉa dày dốc thoải vùng Quảng Ninh. Đề tài cấp cơ sở. Trường Đại học Mỏ - Địa chất, 16.

FLAC3D2.0. (1996). Itasa Consulting Group. Ins. FLAC Version 2.0.

Gong Peilin, Jin Zhongming, Hao, Haijin, (2001). Research on stability test for fully mechanized mining support with large mining heigh. Proceeding of Second International Symposimum on Mining Technology. 246-251.

Gong Peilin, (2008). Surrounding rock cotrol theory and application study of the coal face with greater mining height. China Univestity of Mining and Technolory Press. 1-7.

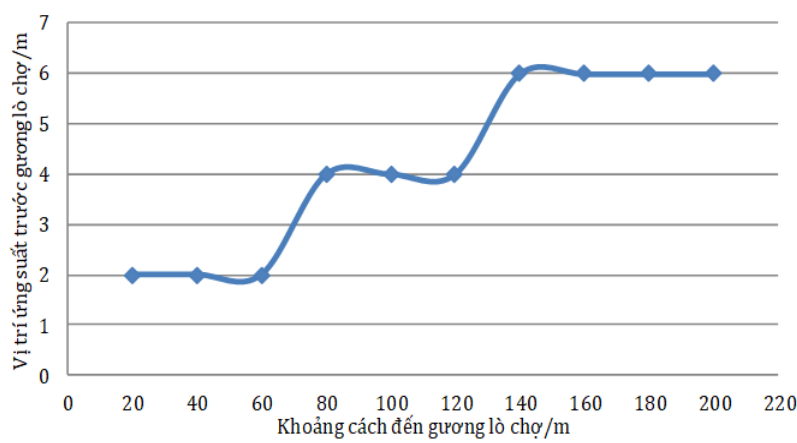

Hình 6. Vị trí ứng suất lớn nhất phía trước gương lò chợ.

He Fulian, Qian Minggao, Zhu Deren, (2011). A study of the interaction between supports and Surrounding rocks in longwall mining face with large mining height. Strata control and Sustainable coal mining. 380-384.

Jun Wang, Pengqi Qiu, Jianguo Ning, Li Zhuang, Shang Yang. (2019) A numerical study of the mining-induced energy redistribution in a coal seam adjacent to an extracted coal panel during longwall face mining: A case study. Enegy Science \& Engineering. https://doi.org/ 10.1002/ese3.553.

Shanxi China National Coal Pingshuo Antaibao Coal Co Ltd. Analysis on the structural characteristics of the No.3 Jingong Mine in Pingshuo Mining Area, Shuozhou City, Shanxi Province. CNKI: SUN: ZGMT.0.2019-12-006.

Tien Dung Le, Xuan Nam Bui (2019). Status and prospects of underground coal mining technology in Vietnam. Inżynieria Mineralna Journal of the Polish Mineral Engineering Society, 44(2): 104-110. 